\title{
ТРАНСНАЦИОНАЛЬНЫЕ БАНКИ: РЕАЛИЗАЦИЯ ЭКОНОМИЧЕСКИХ И ИНСТИТУЦИОНАЛЬНЫХ ИНТЕРЕСОВ
}

\author{
(c) 2019 Михайлов Александр Михайлович \\ доктор экономических наук, профессор \\ Самарский государственный экономический университет, Россия, Самара \\ E-mail:2427994@mail.ru
}

В статье раскрывается содержание и процессы реализации экономических и институциональных интересов транснациональных банков. Рассматривается стратегия реализации интересов транснациональных банков при выходе на финансовые рынки.

Ключевые слова: транснациональные банки, экономические интересы, институциональные интересы, мировые финансовые рынки, банковская конкуренция, институциональная среда

С конца XX столетия мировое хозяйство претерпело значительные качественные изменения, обусловленные глобализационными процессами. Их проводниками стали транснациональные корпорации (ТНК), которые имеют значительное влияние на развитие мировых хозяйственных связей. Наравне с ними осуществляют свою деятельность и транснациональные банки (ТНБ), которые выступают в качестве финансовой опоры для международного бизнеса.

В условиях глобализации ТНБ не только обслуживают финансовые потоки ТНК, но и выступают в качестве посредников на мировом финансовом рынке и обеспечивают движение транснационального капитала, тем самым принимая непосредственное участие практически во всех сферах международных экономических отношений. Масштаб деятельности транснациональных банков оказывает непосредственное влияние не только на национальные экономики стран их дислокации, но и на страны-реципиенты прямых иностранных инвестиций, а, значит, и на мировую экономику в целом.

Для транснациональных банков присущи следующие признаки:

- стабильная прибыль, которая формируется в разных странах;

- оказание сервисных услуг, связанных с обменом капитала;

- развитая заграничная сеть отделений и филиалов;

- постоянно высокая внешняя активность;

- главенствующая роль в общемировом сегменте ссудного капитала.

Сейчас ТНБ без всяких проблем могут профинансировать любой, даже самый крупный проект мирового масштаба. По этой причине их основной задачей является концентрация активов и перевод их в нужный момент в сферы и области, которые могут обеспечить получение максимальной прибыли.

На современном этапе развития ТНБ довольно четко прослеживаются следующие тенденции:

- активная транснационализация активов и тесное переплетение институтов ТНБ с главными финансовыми органами различных государств;

- укрупнение ТНБ за счет альянсов и финансовых союзов с другими корпорациями.

Обозначенные выше тенденции предоставляют транснациональным банкам возможность аккумулировать еще большие размеры мирового капитала. В свою очередь, это ведет к неизбежному увеличению роли ТНБ в мировой экономике и дальнейшему развитию экономической глобализации.

Транснационализация банковского капитала играет значимую роль в механизме функционирования национальной и глобальной экономик. Обладая финансовой информацией, международные банковские институты способны воздействовать на ход экономического и политического развития стран-реципиентов капитала. Процессу транснационализации способствует слияние и поглощение компаний [1]. В частности, известный и влиятельный банк JPMorgan Chase является крупнейшим американским банком, созданным в результате соединения ряда крупнейших финансовых институтов США.

Сама форма транснационализации банковского сектора является формой экспансии 
национальных коммерческих банков и служит ключевым фактором международного потока инвестиций, в том числе в основные фонды [2]. ТНБ участвуют в данных операциях с целью получения прибыли, а также проникновения в зарубежные национальные экономики и захвата новых сфер приложения финансового капитала.

Разработка и реализация стратегии транснационального банка при выходе на новый сегмент, географически и финансово являющегося новым рынком для финансово-кредитной организации, основывается на подходе, при реализации которого у ТНБ должно быть создано определенное конкурентное преимущество. В качестве одного из таких подходов можно назвать финансовое сопровождение деятельности транснациональных компаний, выступающих в качестве клиентов национальных ТНБ и осуществляющих деятельность в зарубежной экономике [3]. Ряд услуг ТНБ оказывают исходя как из специфики деятельности своих клиентов, а также исходя из общих потребностей принимающей капитал экономики, в которой местные финансовые институты подобные услуги оказать, в силу объективных причин, не могут [4]. К этому спектру услуг можно отнести операции по предоставлению кредитов в иностранной валюте в значительном масштабе, сопровождающие сделки и выполнение контрактов в масштабах глобальной торговли.

ТНБ, реализуя свои экономические интересы, могут разрабатывать следующие стратегии:

- поиск наиболее высокодоходного сегмента финансового рынка зарубежной экономики: ТНБ не входят на розничный рынок развитых и развивающихся стран, обслуживаемый национальными финансовыми институтами - cocредотачивают операции на крупных сделках корпоративного сектора;

- активно используют информационные технологии в банковской области, заставляя отечественные банки развивать и включать инновационные технологии в свои финансовые операции;

- разрабатывают мероприятия по проникновению в национальные экономики, реализуя совместно с местным правительством программы инновационного развития особых экономических зон, предприятий, которые, они предполагают кредитовать.

Реализуя свои институциональные интересы, ТНБ способствуют росту уровня эффективности проводимых сделок национальными банками. Отдельные исследователи указывают на разработку мер «защиты» финансовыми властями страны-реципиента своей банковской системы от экспансии зарубежных ТНБ [5]. Укажем, что для банковской системы принимающей страны имеются как положительные, так и отрицательные последствия.

Для успешной реализации институциональных и экономических интересов ТНБ [6], необходимо подготовить институциональную среду как в принимающей стране (которой порой необходимо присутствие глобального финансового института с целью получения финансирования для своей промышленности), так и стране базирования ТНБ. Разумеется, при таком подходе, необходимо учитывать институциональные особенности банковских систем разных стран и обеспечивать безопасное, с точки зрения национальной экономической безопасности, объединение мер регулирования.

Мы предлагаем свое видение реализации банками институциональных и экономических интересов в виде ряда стратегий. Укажем только, что данные подходы к описанию стратегий представлялись и раньше [7], но отдельно, в разбивке по экономическим и институциональным интересам [8]. В данной статье мы попытались создать своего рода агрегатор подходов ТНБ к внешней экспансии своего финансового капитала [9].

ТНБ выявляют предпосылки для старта экспансии на национальные рынки развитых и развивающихся экономик. Разумеется, подходы к проникновению на рынок развитой страны с сильной конкуренцией, присутствием головных отделений ТНБ разительно отличаются от проникновения в финансовую среду развивающихся экономик, но мы выделим общие для обоих подходов черты. От выявления предпосылок зависит вся последующая стратегия ТНБ, поскольку на данном шаге определяется, будет ли экспансия происходить в интересах корпоративных клиентов или же ТНБ намерен развивать сотрудничество с зарубежными финансовыми институтами.

Далее ТНБ выявляет цели и задачи экспансии за рубеж. На форму присутствия банка в иностранном государстве влияет принятие решения: клиентов какого сегмента будет обслуживать ТНБ; спектр каких финансовых услуг предоставлять. Далее определяется тип эконо- 
мики, в которую предполагается осуществить проникновение. Момент принципиальный, поскольку, как указывалось выше, в стране базирования ТНБ, придется приложить массу усилий не только в финансовом плане, но и в политическом, учитывая масштаб и значимость проводимых операций данными финансовыми институтами.

На следующем этапе ТНБ необходимо выявить вероятные проблемы, с которыми он может столкнуться при входе на зарубежный рынок [10]. Определяются как макроэкономические факторы, способные оказать воздействие на деятельность банка (экономическая конъюнктура, инвестиционный климат, состояние банковской системы, кредитно-денежной системы и т.д.), так и факторы, определяющие характер деятельности, свойственный определенному финансовому институту (значение финансовых показателей, размер клиентской базы и прочее).

На последнем этапе стратегии выхода за рубеж, ТНБ определяется организационноправовая форма присутствия на иностранном рынке, а также способ проникновения: в виде прямой экспансии в форме филиала, либо образование альянсов, участие в синдицированном кредитовании, поиск партнеров, размещение своих представительств в непосредственной близости от особых экономических зон или же «заход» под конкретный проект, реализуемый местными органами власти.

Выбирая варианты размещения капитала в зарубежной экономике, в реальном секторе, ТНБ обязательно будет просчитывать эффективность вложения собственных средств.

При анализе финансового состояния объекта инвестирования основными показателями, на которые обращает внимание ТНБ, являются:

1. Коэффициент текущей ликвидности: он характеризует степень обеспеченности текущих обязательств оборотными активами. Показатель определяется отношением суммы оборотных активов (исключая размер просроченной дебиторской задолжности, а также размера задолженности собственников по взносам в Уставный капитал организации и собственных акций, выкупленных у акционеров) к сумме краткосрочных обязательств (за исключением суммы субсидий, дотаций, безвозмездно полученных в пользование активов). Допустимое значение коэффициента текущей ликвидности эмитента принимается более 1,25.
2. Величина собственного капитала в активах компании (коэффициент автономии). Показатель характеризует зависимость организации от внешних источников финансирования. Коэффициент рассчитывается отношением собственного капитала к валюте баланса. Допустимым значением показателя принимается не менее 0,3 .

3. Рентабельность продаж является показателем, отражающим эффективность ключевого направления деятельности хозяйствующего эмитента. Коэффициент можно определить через отношение величины прибыли от продаж (т.е. операционной прибыли) к размеру выручки за тот же период. Пограничное значение рассматриваемого коэффициента не менее 5,45\%.

4. Чистый долг / ЕВIT. Это коэффициент, характеризующий срок возврата заемных средств за счет поступлений от операционной деятельности. Показатель рассчитывается отношением краткосрочных и долгосрочных заимствований.

На рисунке 1 продемонстрирована реализации экономических и институциональных интересов транснациональных банков, осуществляющих финансовую деятельность в развитых и развивающихся странах.

Ситуация, характерная для фигуры NOR наиболее подходит для стран с развивающейся экономикой. Сама развивающаяся экономика привлекательная для ТНБ своей клиентской базой, как в корпоративном секторе, так и в розничном. В каждой экономической системе, при прочих равных благоприятных экономических и институциональных условиях, происходит рост производства и доходов населения. Национальные банки, пока не обладающие спектром высокотехнологичных финансовых инструментов и не включенные в широкое проведение операций с цифровыми финансовыми активами, не могут противопоставить ТНБ каких-либо конкурентных банковских продуктов. Поэтому доходность операций, проводимых ТНБ, а именно кредитование, участие в размещении ценных бумаг (IPO), участие в сделках слияния и поглощения (M\&A) в первое время, в период отсутствия мощных национальных конкурентов и иных ТНБ, на отрезке NO будет возрастать. Однако, повышение доходности финансовых операций в развивающейся экономике обязательно заметят иные ТНБ и далее вступит в силу закон убывающей полезности (снижение доходности на участке OR). Кроме того, длительное 


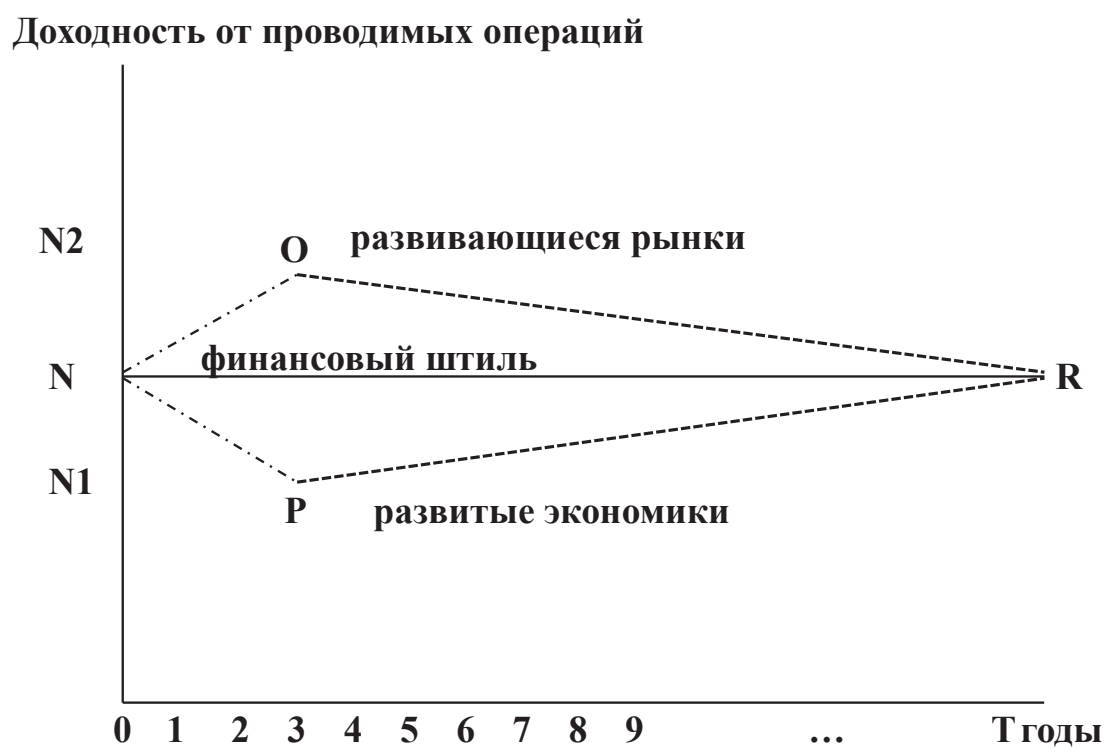

Рисунок 1. График изменения стоимости облигации во времени Источник: составлено автором

присутствие ТНБ на национальном рынке развивающейся страны само по себе способствует появлению национальных конкурентов. Это связано и как с проведением антимонопольной политикой государством принимающей страны, так и с эффектом, назовем его, «перехода голов». Банковский служащий, работающий в ТНБ, получивший достаточный опыт, может быть переманен национальным финансовым институтом, где будет использован накопленный им опыт в кредитовании корпоративного и розничного сектора, передавая и опыт, знания [11] и особенности проведения сделок ТНБ со своими клиентами. Мы даже можем предположить, что момент перехода и передачи знаний таким сотрудником может служить легальной формой «промышленного шпионажа».

Для стран с развитой экономикой ситуация обратная и, она, прежде всего, характеризуется ростом операций на участке PR. Разумеется, при входе на рынок развитой страны, ТНБ столкнется с жесткой конкуренцией со стороны головного офиса национального ТНБ. В такой конкуренции доходы ТНБ, осуществляющего экспансию, будут падать, поскольку затраты на выход на рынок и преодоление барьеров может превышать процентный доход от финансовых операций (участок графика NP). Однако позже, с ростом объема производства за рубежом, вследствие открытия новых филиалов, промышленных компаний последним понадобится новые кредитные ресурсы, а также произойдет рост операций с цифровыми финансовыми активами, объем операций с которыми в развитых странах неуклонно растет. Это и будет обстоятельством, обуславливающим рост доходности ТНБ, занимающегося экспансией на развитый в экономическом плане рынок.

Возможна ситуация и постоянного, подверженного минимальной волатильности дохода, свойственная для ТНБ, открывшего свои представительства в странах, с целью осуществления специфичного, узкого рода деятельности: кредитования отдельных секторов экономики, долгосрочных инфраструктурных проектов - ситуация, по нашему мнению, напоминающая штиль в финансовых колебаниях. Собственно, поэтому и получившей подобное название.

Среди ключевых областей влияния транснациональных банков на национальную экономику можно выделить: стремление ТНБ осуществлять операции с депозитами в экономике реципиенте, их привлечением; определенное ускорение интернационализации информационных знаний и технологий [12], полученных в результате трансграничного кредитования; сделок слияния и поглощений; участия в фондировании операций IPO.

Происходящая унификация и стандартизация процессов регламентирования и контроля банковских институтов, определяет направления работы ТНБ в росте стоимостных и нату- 
ральных объемов внешней торговли политике развивающихся и развитых стран, регламентирующих проведение операций ТНБ, стандартизации банковского законодательства [13].

Все вышеперечисленные процессы деятельности ТНБ позволяют определить основные направления роста конкурентоспособности отечественных банков на глобальном финансовом рынке. К данным направлениям мы можем отнести: диверсификацию банковских продуктов; изучение конъюнктуры зарубежного рынка; создание баз данных клиентов; сокращение и сведения к минимуму постоянных издержек выхода на зарубежный рынок; рост доступности и упрощение операций, связанных с банковскими услугами.

Таким образом, можно утверждать, что институциональные и экономические интересы, проявляемые в результате деятельности ТНБ, состоят в регулярной балансировке между преимуществами вложения в высокодоход- ные проекты и сопутствующим им рискам. ТНБ в условиях информатизации и глобализации финансово-хозяйственной деятельности разрабатывают стратегии осведомленности об операциях банков-конкурентов, повышают скорость реагирования на проявление последствий финансовых кризисов, осуществляют диверсификацию банковских продуктов за счет использования информационных технологий и многое другое.

Следует указать, что для самих ТНБ характерны процедуры объединения капиталов, а также взаимное приобретение активов, благодаря чему создается система международных корреспондентских отношений. Результатом данных процессов служит создание интегрированных финансовых систем, по масштабам операций и значимости заключаемых сделок иногда превосходящим финансовые возможности отдельных стран.

\section{Библиографический список}

1. Левченко Л.В., Городнов В.А. Слияние и поглощение банков и кредитных организаций //Вопросы экономики и права. 2019. № 3. С. 38-44.

2. Никулина О.В., Букреева Е.И. Разработка методов и инструментов управления финансовой устойчивостью коммерческого банка в условиях мирового экономического кризиса // Экономика и предпринимательство. 2015. № 12-1. С. 604-608.

3. Ромашова А.И. Роль транснациональных банков в современной мировой экономике [Текст] / А.И. Ромашова [и др.] // Экономика и управление: проблемы, тенденции, перспективы развития: Материалы Междунар. науч.-практ. конф. (Чебоксары, 14 нояб. 2015 г.) / Редкол.: О.Н. Широков [и др.].- Чебоксары: ЦНС «Интерактив плюс», 2015.-С. 215

4. Розинский И.А. Иностранные банки и национальная экономика.- М.: ЗАО «Издательство экономика», 2009.- С. 113.

5. Williams, $B$. Positive theories of multinational banking: eclectic theory versus internalization theory. //Journal of Economics Surveys. - 1997. - № 11 (1).- P. 58.

6. Мишин А.Ю. Экономические и институциональные интересы коммерческих банков в современных социально-экономических условиях //Экономические науки. 2019. № 1 (170). С. 17-22.

7. Kwan S. H., Eisenbeis R.A. An Analysis of Inefficiencies in Banking// Journal of Banking and Finance, 19, June 1999.- Р.28-41; Скляр Л. Конкурирующие концепции глобализации // Социальные и гуманитарные науки. Серия 11. Социология. - 2002.- № 4.- С. 22-30.

8. Михайлов А.М. Реализация институциональных интересов в процессе банковской деятельности //Экономические науки. 2019. № 173. С. 17-21.

9. Саркисянц А. Пути развития private banking и его российские особенности // Бухгалтерия и банки. - 2010.№ $1 .-$ С. $18-26$.

10. Михайлов А.М., Патрин С.М. Управление рыночными рисками розничного банка // Вестник Самарского государственного экономического университета. 2015. № 5 (127). С. 104-110.

11. Коновалова М.Е., Кузьмина О.Ю., Михайлов А.М. Формирование человеческого капитала на основе информации и знаний //Экономика и управление собственностью. 2018. № 1. С. 57-61.

12. Коновалова М.Е., Михайлов А.М.. Кузьмина О.Ю. Прогнозирование развития фондовых рынков в условиях становления цифровой экономики //Вестник Самарского государственного экономического университета. 2018. № 11 (169). С. 13-19.

13. Макушкин А.Г. Финансовая глобализация Постиндустриальный мир: центр, периферия, Россия. М., 2018. Сборник 1.С. 168. 